\title{
PENGEMBANGAN SOAL MATEMATIKA MODEL TIMSS \\ UNTUK MENDUKUNG PEMBELAJARAN MATEMATIKA SMP KELAS VII \\ KURIKULUM 2013
}

\author{
M. Andy Rudhito dan D. Arif Budi Prasetyo \\ FKIP Universitas Sanata Dharma, Yogyakarta \\ Email: rudhito@usd.ac.id
}

\begin{abstract}
Abstrak: Penelitian ini bertujuan untuk menghasilkan soal matematika model TIMSS yang valid dan praktis untuk siswa SMP berdasarkan Kurikulum 2013. Metode penelitian yang digunakan adalah penelitian pengembangan. Proses pendesainan soal sebagai instrumen penilaian dilakukan dengan prototyping. Prototyping meliputi dua tahap. Prototipe I merupakan hasil desain dan penyusunan soal-soal oleh peneliti sendiri, sedang prototipe II revisi dari prototipe I berdasarkan masukan dari pakar, teman sejawat, dan guru matematika, yang berupa catatan validator dan notulensi diskusi. Hasil penelitian menunjukkan bahwa buku soal yang disusun dengan pengelompokan bab mengikuti ranah materi seperti dalam TIMSS, yakni bilangan, geometri, aljabar, data dan peluang. Buku soal untuk siswa tidak perlu ada tulisan mengenai ranah materi, topik pokok, dan ranah kognitif. Masukan untuk perbaikan dari $F G D$ adalah soal sebaiknya diawali dari yang mudah, sedang, baru yang sulit. Penulisan soal pilihan ganda lebih baik tidak menggunakan kalimat tanya, melainkan dengan membuat pernyataan yang memuat titik-titik, baik di tengah atau di akhir kalimat. Soal sebaiknya tidak memuat pernyataan implikasi.
\end{abstract}

Kata kunci: Pengembangan soal, matematika SMP, TIMSS, Kurikulum 2013

\section{DEVELOPING THE TIMSS MATH PROBLEM MODEL TO SUPPORT THE MATHEMATICS LEARNING IN GRADE VII USING THE 2013 CURRICULUM}

\begin{abstract}
This study was aimed to produce a valid and practical TIMMS math problem model for junior high school students using the 2013 curriculum. The study used the research and development design. The design process of the problems as assessment instruments was carried out through prototyping involving two stages. Prototype I was the design product and the problem development done by the researchers themselves, while Prototype II was the revision of Prototype I based on the feedback provided by experts, colleagues, and Mathematics teachers in the form of validators' notes and the minutes taken from discussions. The findings showed that the book of math problems was written by grouping the chapters following the materials domains as those in TIMSS, that is, numbers, geometry, algebra, data, and probability. For the student book, it was not nsecessary to write the materials domain, the essential topics, and the cognitive domain. The feedback from the FGD was that the problems should be arranged from the easiest ones to the most difficult ones. The multiple choice items should not be written in the form of questions, but in the form of incomplete sentences with the blanks in the middle or the end of the sentences. The items should not ask about implication.
\end{abstract}

Keywords: Development of problems, junior high school mathematics, TIMSS, Curriculum 2013

\section{PENDAHULUAN}

Dalam uji kompetensi siswa di bidang Matematika berskala internasional, seperti TIMSS

= Trends International Mathematics and Science Study (http://timss.bc.edu/), prestasi siswa-siswa
Indonesia masih berada pada ranking bawah. Salah satu latar belakang dikeluarkan kebijakan Kurikulum 2013 adalah rendahnya kompetensi SDM generasi penerus yang tercermin dalam hasil TIMSS. Implementasi Kurikulum 2013 (Ke- 
mendikbud, 2013a) menghendaki agar penilaian berbasis kompetensi mencakup penilaian sikap, pengetahuan, keterampilan yang pelaksanaannya terintegrasi dengan proses pembelajaran dan menjadikan portofolio sebagi instrumen utama. Bila dicermati tujuan mata pelajaran matematika SMP/ MTs (Kemendikbud, 2013a) maka pada intinya adalah setelah belajar matematika siswa dapat berkembang sikap, pemahaman dan keterampilannya yang sesuai dengan karakteristik matematika. Dalam hal berkembangnya (tumbuhnya) sikap, siswa diharapkan dapat berpikir kritis, logis, analitik dan kreatif, menghargai kegunaan matematika dalam kehidupan yang ditunjukkan dengan tumbuhnya rasa ingin tahu, perhatian, dan minat dalam mempelajari matematika, ulet dan percaya diri dalam memecahkan masalah kehidupannya sehari-hari. Dalam hal berkembangnya pengetahuan, siswa diharapkan agar dapat memahami konsep matematika, menjelaskan keterkaitan antar konsep dan mengaplikasikannya dalam kegiatan pemecahan masalah. Dalam hal berkembangnya keterampilan, siswa diharapkan dapat memecahkan masalah, dan mengkomunikasikan gagasan serta budaya bermatematika, menggunakan penalaran pada pola dan sifat, melakukan manipulasi matematika dalam membuat generalisasi, menyusun bukti, atau menjelaskan gagasan dan pernyataan matematika.

Dalam TIMSS kerangka penilaian kemampuan bidang matematika yang diuji menggunakan istilah dimensi dan domain (ranah). TIMSS untuk siswa SMP terbagi atas dua ranah, yaitu dimensi materi dan dimensi kognitif dengan memperhatikan kurikulum yang berlaku di negara bersangkutan. Dalam TIMSS 2011 Assessment framework (Mullis, I., et.al, 2009) disebutkan bahwa dimensi materi terdiri atas empat domain, yaitu: bilangan, aljabar, geometri, data dan peluang. Tiap domain materi diperinci lebih lanjut dalam beberapa topik, misalnya domain materi bilangan meliputi topik bilangan cacah, pecahan dan desimal, bilangan bulat, perbandingan, proporsi, dan presentase. Dimensi kognitif terdiri atas tiga domain yaitu mengetahui fakta dan prosedur (pengetahuan), menggunakan konsep dan memecahkan masalah rutin (penerapan) dan memecahkan masalah nonrutin (penalaran). Dimensi kognitif dimaknai sebagai perilaku yang diharapkan dari siswa ketika mereka berhadapan dengan domain matematika yang tercakup dalam dimensi materi. Dalam dimensi kognitif, pemecahan masalah merupakan fokus utama dan muncul dalam soal-soal tes yang terkait dengan hampir semua topik dalam tiap domain materi. Keempat domain dalam dimensi kognitif merupakan perilaku yang diharapkan dari siswa ketika mereka berhadapan dengan domain matematika yang tercakup dalam dimensi materi. Soal-soal tersebut dirancang sedemikian rupa sehingga kedua dimensi penilaian, yaitu materi dan kognitif dapat teramati. Soal-soal matematika dalam studi TIMSS mengukur tingkatan kemampuan siswa dari sekedar mengetahui fakta, prosedur atau konsep, lalu menerapkan fakta, prosedur atau konsep tersebut hingga menggunakannya untuk memecahkan masalah yang sederhana sampai masalah yang memerlukan penalaran tinggi.

Hasil penilaian kemampuan matematika siswa Indonesia dalam studi TIMSS (Puspendik, 2006) pada intinya merekomendasikan agar: i) memperbaiki proses pembelajaran di sekolah dengan meningkatkan porsi bernalar, memecahkan masalah, berargumentasi dan berkomunikasi, ii) memperbaiki standar dan praktek penilaian hasil belajar siswa secara nasional dan sehari-hari di kelas dengan mengukur keterampilan teknis baku, kemampuan bernalar, pemecahan masalah dan berkomunikasi secara seimbang, iii) mempelajari budaya dan menginternalisasi konteks budaya dalam pembelajaran agar wawasan siswa semakin luas.

Hasil TIMSS yang rendah tersebut tentunya disebabkan oleh banyak faktor. Salah satu faktor penyebabnya antara lain buku ajar yang digunakannya. Jika kita mencermati buku ajar untuk siswa yang digunakan di sekolah-sekolah, termasuk buku-buku yang sudah disiapkan untuk mendukung Kurikulum 2013, seperti Buku Matematika Kelas VII Kurikulum 2013 (Kemendikbud, 2013b), tidak mudah untuk menemukan soal-soal latihan yang karakteristiknya seperti soal-soal di TIMSS. Padahal, buku-buku tersebutlah yang banyak digeluti siswa dalam pembelajaran sehari-hari. Silabus yang disusun pada umumnya menyajikan instrumen penilaian hasil belajar yang substansinya kurang dikaitkan dengan konteks kehidupan yang dihadapi siswa dan kurang memfasilitasi siswa dalam me-

Pengembangan Soal Matematika Model TIMSS untuk Mendukung Pembelajaran Matematika SMP Kelas VII Kurikulum 2013 
ngungkapkan proses berpikir dan berargumentasi. Keadaan itu tidak sejalan dengan karakteristik dari soal-soal pada TIMSS yang substansinya kontekstual, menuntut penalaran, argumentasi dan kreativitas dalam menyelesaikannya. Untuk itu perlu diupayakan berbagai alternatif dan inovasi dalam rangka meningkatkan kemampuan matematika siswa kita. Salah satunya dengan mengembangkan soal matematika model TIMSS untuk sekolah menengah berdasarkan Kurikulum 2013.

Penelitian pengembangan soal model TIMSS untuk sekolah menengah pertama, khususnya untuk soal penalaran telah dilakukan Rizta, dkk (2013). Penelitian tersebut menggunakan metode research and development, dan kevalidan diketahui dari hasil penilaian validator pada lembar validasi yang menyatakan soal-soal yang dikembangkan telah baik berdasarkan content (sesuai dengan kurikulum dan materi), construct (sesuai dengan karakteristik penalaran siswa), dan bahasa (sesuai dengan kaidah bahasa yang berlaku). Sejenis dengan pengembangan soal model TIMSS juga telah dikembangkan soal model PISA (Program for International Student Assessment). Beberapa di antaranya dalam penelitian Anisah dkk (2011), Johar (2012), dan Aisyah (2013). Anisah dkk (2011) melakukan pengembangan soal matematika model PISA pada konten quantity untuk mengukur kemampuan penalaran matematis siswa sekolah menengah pertama. Penelitian tersebut berfokus pada kebutuhan untuk kuantifikasi, yang meliputi pemahaman ukuran relatif, pengakuan pola numerik, dan kemampuan untuk menggunakan angka untuk mewakili atribut kuantitatif objek dunia nyata. Soal didesain berdasarkan framework soal PISA dan diadaptasikan dengan kurikulum KTSP seperti yang berlaku saat itu. Johar (2012) membahas kaitanantara literasi matematika, domain PISA, level kemampuan matematika pada soal PISA dan upaya meningkatkan skor PISA untuk siswa di Indonesia. Penelitian Aisyah (2013) bertujuan menghasilkan soal tipe PISA yang valid dan praktis pada siswa Sekolah Menengah Pertama dengan metode penelitiannya penelitian pengembangan (development research). Dalam penelitian tersebut ini telah menghasilkan perangkat soal tipe PISA sejumlah 14 butir soal berbentuk uraian non ob- jektif yang memiliki enam level kesulitan dalam PISA yang valid dan praktis, dan perangkat soal tipe PISA mempunyai efek potensial yaitu dapat memicu siswa untuk mengeksplor kemampuanmatematis siswa.

Sebagai langkah awal pengembangan soal-soal ini telah dilakukan analis kompetensi dasar dan materi yang ada di Kurikulum 2013 dan TIMSS. Penelitian menunjukkan bahwa ada beberapa kompetensi dasar dan materi pokok dalam Kurikulum 2013 Matematika Kelas VII tetapi tidak dituntut dalam TIMSS Eighth-Grade 2011, di antaranya adalah materi pokok himpunan dan aritmatika sosial. Beberapa materi yang ada di Kurikulum 2013 juga pengelompokannya tidak sesuai dengan di TIMSS Eighth-Grade 2011, di antaranya materi pola bilangan. Materi yang ada di kedua dokumen secara umum lebih lengkap dan mendalam yang ada di TIMSS Eighth-Grade 2011. Materi Patern Patterns dan Algebraic Expressiondalam TIMSS yang mestinya merupakan materi dasar dalam aljabar, justru baru ada di kelas VIII dalam Kurikulum 2013.Sebagai langkah lebih dalam pengembangan soal-soal ini, akan dikembangkan soal-soal model TIMSS yang dapat digunakan dalam pembelajarannya di kelas. Penelitian ini bertujuan untuk menghasilkan soal matematika model TIMSS yang valid dan praktis, untuk siswa SMP, berdasarkan Kurikulum 2013.

\section{METODE}

Penelitian ini dilaksanakan pada bulan Juli sampai dengan November 2015. Metode penelitian yang digunakan adalah penelitian pengembangan atau development research tipe formative evaluation (Tessmer, 1993). Penelitian ini mengembangkan soal-soal matematika SMP model TIMSS yang valid untuk mendukung pelaksanaan pembelajaran matematika SMP Kurikulum 2013. Penelitian ini terdiri dari dua tahap yaitu preliminary dan tahap formatif evaluation yang meliputi self evaluation dan expert reviews.

\section{Tahap Penelitian}

Tahap Preliminary

Persiapan: Pada tahap ini dilakukan analisis terhadap Kurikulum, Buku BSE Matematika Kelas VII dan Buku-buku TIMSS yang terkait. Perancangan dan Penyusunan: Pada tahap ini- 
dilakukan perancangan dan penyusunan kisi-kisi dan soal-soal oleh peneliti dengan mengacu pada soal-soal TIMSS. Perancangan dan penyusunan dengan memperhatikan materi pokok Kurikulum 2013 Bidang Studi Matematika Sekolah Menengah Pertama Kelas VII dan domaian pada TIMSS, yang meliputi ranah materi dan ranah kognitif. Ranah materi meliputi: Bilangan, Aljabar, Geometri, Data dan Peluang, sedangkan ranah kognitif meliputi: pengetahuan, penerapan dan penalaran.

\section{Tahap Formatif Evaluation}

Tahap Self Evaluation: Pada tahap ini dilakukan penilaian oleh peneliti sendiri terhadap hasil desain dan penyusunan soal-soal model TIMSS untuk mendukung pembelajaran matematika SMP kelas VII Kurikulum 2013. Dari tahap ini akan diperoleh prototipe I.

Tahap Expert Reviews: Pada tahap ini rancangan dan susunan soal yang dibuat oleh peneliti divalidasi oleh pakar dan guru matematika sebagai stakeholders. Ada dua pakar dan tiga guru matematika yang akan terlibat dalam tahap ini. Produk yang dirancang dan disusun akan dilihat, dinilai, dan dievaluasi. Uji validitas yang dilakukan adalah uji validitas content, uji validitas construct, dan uji validitas bahasa. Saran-saran dari validator digunakan untuk merevisi rancangan dan susunan soal yang dibuat peneliti. Tanggapan dan saran dari validator tentang rancangan dan susunan soal yang telah dibuat ditulis pada lembar validasi sebagai bahan untuk merevisi dan menyatakan bahwa soal-soal yang dikembangkan tersebut telah valid. Dari tahap ini dan juga setelah melalui focus group discussion (FGD). FGD ini dimaksudkan untuk mengklarifikasi masukan, mencari solusi perbaikan soal, baik secara teoritis maupun secara praktis nantinya di sekolah. Prototipe I direvisi dan akan diperoleh prototipe II.

Teknik pengumpulan data yang digunakan dalam penelitian ini adalah sebagai berikut. Dokumentasi: Dokumen yang digunakan dalam hal ini adalah kurikulum yang sesuai, yaitu Kurikulum 2013 Bidang Studi Matematika Sekolah Menengah Pertama Kelas VII dan soal-soal TIMSS yang dipublikasikan tahun 2007 dan 2011 (Pierre \& John, 2009, 2013). Walkthrough: Walkthrough dilakukan pada saat expert review oleh pakar dan guru matematika untuk memberikan penilaian dan saran atau masukan tentang content, construct dan bahasa. Penilaian diberikan dengan memberikan skor dengan kategori seperti dalam Tabel 1.

Tabel 1. Skor Penilaian Validasi dan Kategorinya

\begin{tabular}{cc}
\hline Skor & Kategori \\
\hline 0 & Kurang Sekali \\
1 & Kurang \\
2 & Cukup \\
3 & Baik \\
4 & Baik Sekali \\
\hline
\end{tabular}

Saran yang diberikan melalui uraian secara terbuka, baik saran untuk secara umum, maupun saran secara khusus untuk soal tertentu. Data $F G D$ dikumpulkan melalui notulen $F G D$ dan perekaman video.

Teknik analisis data yang digunakan adalah teknik deskriptif. Analisis tersebut digunakan untuk menganalisis data setelah validasi dengan cara merevisi berdasarkan catatan validator, baik pada validasi pakar (walktrough) maupun catatan notulen saat $F G D$. Hasil dari analisis inilah yang akan digunakan untuk merevisi soal-soal matematika tipe TIMSS yang dibuat oleh peneliti.

\section{HASIL DAN PEMBAHASAN}

\section{Analisis Kurikulum dan TIMSS}

Dalam analisis ini diperoleh beberapa hasil seperti dalam Rudhito dan Prasetyo (2015), yaitu bahwa ada beberapa kompetensi dasar dan materi pokok dalam Kurikulum 2013 Matematika Kelas VII tetapi tidak dituntut dalam TIMSS, di antaranya adalah materi pokok himpunan dan aritmatika sosial. Beberapa materi yang ada di Kurikulum 2013 juga pengelompokannya tidak sesuai dengan di TIMSS, di antaranya materi pola bilangan. Materi Patern Patterns dan Algebraic Expression dalam TIMSS yang mestinya merupakan materi dasar dalam aljabar, justru baru ada di kelas VIII dalam Kurikulum 2013.

\section{Perancangan dan Penyusunan Soal oleh Pe- neliti}

Penyusunan diawali dengan mempelajari soal-soal TIMSS yang tahun 2007 (Foy \& Olson 2009) dan soal-soal TIMSS yang tahun 2011 (Foy

Pengembangan Soal Matematika Model TIMSS untuk Mendukung Pembelajaran Matematika SMP Kelas VII Kurikulum 2013 
\& Olson 2013). Soal-soal yang sesuai diadaptasi dan dikelompokkan berdasarkan materi pokok yang ada di Buku Matematika Kurikulum 2013 (Kemendikbud, 2013b). Dari adaptasi dan penyesuaian ini disusun soal dengan pembagian bab mengikuti materi pokok seperti dalam kurikulum maupun dalam buku paket BSE. Pembagian bab tersebut meliputi bab Himpunan, Bilangan, Garis dan Sudut, Perbandingan dan Skala, Persamaan dan Pertidaksamaan Linear Satu Variabel, Aritmatika Sosial, Transformasi, Statistika, Peluang. Berikut berturut-turut diberikan salah satu contoh soal dari Bab II Bilangan dalam bentuk soal pilihan ganda dan uraian.

\section{Self Evaluation (Prototipe I)}

Dari proses adaptasi di atas, mengingat luaran penelitian ini adalah Buku Suplemen Pelajaran Matematika Kelas VII Kurikulum 2013 yang berisi soal-soal matematika model TIMSS, maka penulisan soal-soal dengan format seperti di atas dirasa kurang tepat. Untuk buku soal yang dihadapi siswa tidak perlu ada bagian-bagian yang menuliskan tentang ranah materi, topik pokok dan ranah kognitif. Siswa langsung berhadapan den- gan soal-soal dan petunjuk pengerjaannya, baik yang berupa pilihan ganda ataupun essay (uraian). Sedangkan keterangan mengenai ranah-ranah di atas hanya perlu diketahui guru, yang nantinya akan disajikan dalam buku soal untuk guru. Untuk itu soal yang telah disusun peneliti sendiri, sebelum divalidasi oleh pakar (dosen) maupun guru matematika sebagai stakeholders, direvisi terlebih dahulu. Revisi meliputi pembagian pengelompokkan soal menjadi bab-bab yang mengikuti ranah materi dalam soal TIMSS yang diadaptasi, yaitu Bilangan, Geometri, Aljabar, Data dan Peluang. Hal ini mengingat agar materi soal yang akan dilatihkan dibatasi pada topik pokok dalam TIMSS. Dari proses ini dihasilkan prototipe I untuk buku soal. Jumlah soal yang disusun dan pembagiannya dalam ranah materi dan ranah kognitif diberikan dalam Tabel 2.

Berikut diberikan contoh bentuk revisi soal seperti Contoh 1 di atas setelah self evaluation.

\section{Revisi Prototipe I berdasar Validasi dan FGD (Prototipe II)}

Dari prototipe I di atas selanjutnya divalidasi oleh pakar dan guru matematika. Ada dua

\begin{tabular}{|c|c|c|}
\hline \multicolumn{3}{|c|}{ BAB II BILANGAN } \\
\hline Ranah Materi & $\begin{array}{l}\text { Topik Pokok } \\
\end{array}$ & Ranah Kognitif \\
\hline Bilangan & Bilangan Bulat & Pemahaman \\
\hline \multicolumn{3}{|c|}{$\begin{array}{l}\text { Manakah berikut ini yang menyatakan BILANGAN } 36 \text { merupakan hasil kali faktor prima } \\
\text { A. } 6 \times 6 \\
\text { B. } 4 \times 9 \\
\text { C. } 4 \times 3 \times 3 \\
\text { D. } 2 \times 2 \times 3 \times 3\end{array}$} \\
\hline \\
\hline \multicolumn{3}{|c|}{ 1.11 Mengepak telur dalam kotak } \\
\hline Ranah Materi & Topik Pokok & Ranah Kognitif \\
\hline Bilangan & Bilangan Cacah & Penerapan \\
\hline \multicolumn{3}{|c|}{$\begin{array}{l}\text { Budi memasukkan telur ke dalam kotak. } \\
\text { Setiap kotak dapat memuat } 6 \text { butir telur. } \\
\text { Ia memiliki } 94 \text { butir telur. } \\
\text { Berapa minimal banyak kotak yang ia butuhkan untuk semua telurnya? }\end{array}$} \\
\hline
\end{tabular}

Gambar 1. Contoh Soal Materi Bilangan Sebelum Self Evaluation 
Tabel 2. Jumlah Soal dalam Ranah Materi dan Kognitif

\begin{tabular}{clccc}
\hline Tipe Soal & \multicolumn{1}{c}{ Materi } & Pengetahuan & Penerapan & Penalaran \\
\hline Pilihan Ganda & Bilangan & 15 & 15 & 2 \\
& Geometri & 5 & 11 & 4 \\
& Aljabar & 12 & 5 & 1 \\
& Data dan Peluang & 4 & 6 & 4 \\
Esai & Bilangan & 3 & 7 & 6 \\
& Geometri & 0 & 7 & 3 \\
& Aljabar & 3 & 2 & 1 \\
& Data dan Peluang & 1 & 7 & 3 \\
\hline Jumlah & & 43 & 60 & 24 \\
\hline
\end{tabular}

\section{BAB I BILANGAN}

PILIHAN GANDA: Pilihlah salah satu jawaban yang kamu anggap tepat.

1. Manakah berikut ini yang menyatakan bilangan 36 merupakan hasil kali faktor prima?
A. $6 \times 6$
B. $4 \times 9$
C. $4 \times 3 \times 3$
D. $2 \times 2 \times 3 \times 3$

ESAI: Kerjakan soal-soal berikut dengan menuliskan langkah-langkahnya. -..

4. Kimi memasukkan telur ke dalam kotak. Setiap kotak dapat memuat 6 butir telur. Ia memiliki 94 butir telur.Berapa minimal banyak kotak yang ia butuhkan untuk semua telurnya?

$\cdots$

Gambar 2. Contoh Soal Materi Bilangan Sesudah Self Evaluation

pakar dari Pendidikan Matematika Universitas Sanata Dharma, sedangkan guru matematika yang terlibat ada tiga guru masing-masing dari SMP Pangudi Luhur, Srumbung Magelang, SMP Kanisius Sleman, dan SMP Pangudi Luhur, Wedi Klaten. Dari proses validasi dan focus group discussion ( $F G D$ ), prototipe I direvisi dan diperoleh prototipe II. Dokumen yang digunakan dalam tahap ini adalah berupa lembar penilaian, saran dan notulensi $F G D$.Hasil penilaian secara umum dari kelima validator diberikan dalam Tabel 3 .

Dari hasil penilaian di atas tampak dari segi materi sudah baik sekali, hampir tidak ada masalah, dari segi construct ada beberapa hal yang perlu diperbaiki, sedangkan dari segi bahasa agak banyak yang perlu diperbaiki.
Tabel 3. Hasil Penilaian Validasi

\begin{tabular}{ccc}
\hline Jenis Validasi & Skor & Kategori \\
\hline Validasi Content & 3,54 & Baik Sekali \\
Validasi Construct & 2,96 & Baik \\
Validasi Bahasa & 2,68 & Sedang \\
\hline
\end{tabular}

Dari hasil penilaian validasi saran dan notlen $F G D$ diperoleh beberapa hal secara umum yang harus diperbaiki seperti dalam Tabel 4.

Setelah direvisi sesuai dengan hasil validasi dan FGD, berikut diberikan beberapa contoh soal dari Bab Bilangan dan Bab Geometri.

\section{Pembahasan}

Dari hasil FGD dan revisi prototipe I di atas, ada beberapa hal yang dapat dibahas. Beberapa hal yang menjadi pedoman penyusunan soal yang baik menurut dosen dan guru matematika ada yang tidak begitu saja berlaku di soal- 
Tabel 4. Saran dan Perbaikan Soal

\begin{tabular}{|c|c|c|}
\hline No. & $\begin{array}{c}\text { Saran } \\
\end{array}$ & $\begin{array}{l}\text { Perbaikan } \\
\end{array}$ \\
\hline 1. & $\begin{array}{l}\text { Soal sebaiknya diawali dari yang relatif } \\
\text { mudah dulu, sedang, baru yang sulit. }\end{array}$ & $\begin{array}{l}\text { Saran diterima, karena sesuai dengan } \\
\text { psikologi siswa saat mengerjakan soal nanti. }\end{array}$ \\
\hline 2. & $\begin{array}{l}\text { Penulisan soal pilihan ganda lebih baik } \\
\text { tidak menggunakan kalimat tanya, } \\
\text { melainkan dengan membuat titik-titik (... ), } \\
\text { baik di tengah atau diakhir kalimat. }\end{array}$ & $\begin{array}{l}\text { Saran diterima, karena secara praktek lebih } \\
\text { mudah diterima siswa. }\end{array}$ \\
\hline 3. & $\begin{array}{l}\text { Soal sebaiknya tidak memuat pernyataan } \\
\text { "jika ... maka ..." }\end{array}$ & $\begin{array}{l}\text { Saran diterima, karena dapat memunculkan } \\
\text { perdebatan di antara guru terkait kebenaran } \\
\text { kalimat bentuk implikasi. }\end{array}$ \\
\hline 4. & Pilihan jawaban hendaknya dibuat setipe. & $\begin{array}{l}\text { Saran ditinjau kembali sesuai dengan } \\
\text { kondisi dan maksud soal. }\end{array}$ \\
\hline 5. & $\begin{array}{l}\text { Banyak opsi jawaban sebaiknya dibuat } \\
\text { sama, yaitu ada } 4 \text { pilihan ganda(untuk } \\
\text { tingkat SMP). }\end{array}$ & $\begin{array}{l}\text { Saran diterima, untuk kekonsistenan dan } \\
\text { sesuai dengan kemamuan anak SMP }\end{array}$ \\
\hline 6. & $\begin{array}{l}\text { Perlu dipertimbangkan pengecoh jawaban } \\
\text { yang baik }\end{array}$ & $\begin{array}{l}\text { Saran ditinjau kembali sesuai dengan } \\
\text { kondisi dan maksud soal. }\end{array}$ \\
\hline 7. & $\begin{array}{l}\text { Posisi tabel kemunculannya sebaiknya } \\
\text { disesuaikan dengan kemunculannya dalam } \\
\text { kalimat pertanyaannya. }\end{array}$ & $\begin{array}{l}\text { Saran diterima, karena sesuai dengan } \\
\text { psikologi siswa saat mengerjakan soal nanti. }\end{array}$ \\
\hline 8. & $\begin{array}{l}\text { Nama atau benda yang sudah dipakai dalam } \\
\text { suatu soal sebaiknya jangan dipakai lagi. }\end{array}$ & $\begin{array}{l}\text { Saran diterima, walaupun sebenarnya tidak } \\
\text { terlalu prinsip. }\end{array}$ \\
\hline 9. & $\begin{array}{l}\text { Kesalahan istilah yang resmi perlu } \\
\text { diperbaiki. }\end{array}$ & Diperbaiki sesuai saran. \\
\hline 10. & $\begin{array}{l}\text { Kesalahan ketik masih ada yang perlu } \\
\text { diperbaiki }\end{array}$ & $\begin{array}{l}\text { Soal diperiksa kembali dengan seksama } \\
\text { secara keseluruhan. }\end{array}$ \\
\hline 11. & Ada beberapa soal yang sama & Dipilih soal-soal yang tidak sama \\
\hline 12. & $\begin{array}{l}\text { Tanda kali sebaiknya menggunakan simbol } \\
\text { perkalian } \times \text {, bukan menggunakan huruf } x\end{array}$ & $\begin{array}{l}\text { Soal diperiksa kembali dengan seksama } \\
\text { secara keseluruhan. }\end{array}$ \\
\hline 13. & $\begin{array}{l}\text { Perlu diperiksa lagi jawaban yang tersedia, } \\
\text { karena ada soal yang tidak ada jawabannya. }\end{array}$ & $\begin{array}{l}\text { Diperbaiki dengan memastikan ada jawaban } \\
\text { untuk setiap soal }\end{array}$ \\
\hline 14. & $\begin{array}{l}\text { Beberapa gambar perlu diperiksa lagi, } \\
\text { karena ada yang kurang jelas dan kurang } \\
\text { tepat. }\end{array}$ & $\begin{array}{l}\text { Diperbaiki sesuai saran, dengan memeriksa } \\
\text { semua gambar }\end{array}$ \\
\hline 15. & $\begin{array}{l}\text { Perlu tanda titik untuk memisahkan } \\
\text { bilangan yang lebih dari } 3 \text { digit. }\end{array}$ & $\begin{array}{l}\text { Diperbaiki sesuai saran, karena akan lebih } \\
\text { memudahkan siswa dalam membaca }\end{array}$ \\
\hline 16. & $\begin{array}{l}\text { Sumbu-sumbu koordinat perlu diberi nama } \\
\text { atau tanda. }\end{array}$ & Diperbaiki sesuai saran \\
\hline
\end{tabular}

soal TIMSS. Soal dalam dokumen TIMSS tidak selalu urut diawali dari yang relatif mudah dulu, sedang, baru yang sulit. Hal ini mungkin karena ada perbedaan sudut pandang mengenai soal yang sulit atau tidak dari versi guru maupun dari versi TIMSS. Dalam dokumen TIMSS penulisan soal pilihan ganda banyak yang menggunakan kalimat tanya, sementara menurut guru dari hasil mereka mengikuti diklat, sebaiknya tidak menggunkan kalimat tanya, melainkan dengan membuat pernyataan yang memuat titik-titik (...), baik di tengah atau diakhir kalimat. Hal ini juga belum diketahui alasan dengan jelas mengenai perbedaan kedua hal ini. Menurut guru soal sebaiknya tidak memuat pernyataan "jika ... maka ... ". Hal ini dikarenakan dapat memancing diskusi mengenai nilai kebenaran dalam logika untuk kalimat dengan bentuk implikasi.

Mengenai pilihan jawaban hendaknya dibuat setipe dan perlu dipertimbangkan pengecoh jawaban yang baik, nampaknya hal ini agak berbeda dengan yang ada di dokumen TIMSS. Nampaknya dokumen TIMSS lebih mengantisipasi terhadap jalan pikiran siswa yang mungkin bervariasi, tanpa pemikiran dalam trik-trik menjawab soal pilihan ganda. Sementara pandangan 


\section{Contoh Soal Bab Bilangan dan Bab Geometri:}

\section{BAB I BILANGAN}

PILIHAN GANDA: Pilihlah salah satu jawaban yang tepat.

1. Berikut ini yang menyatakan bilangan 36 sebagai hasil kali faktor prima adalah ....
A. $6 \times 6$
B. $4 \times 9$
C. $4 \times 3 \times 3$
D. $2 \times 2 \times 3 \times 3$

ESSAY: Kerjakan soal-soal berikut dan tuliskan langkah-langkahnya.

1. Tempatkan empat bilangan 3, 5,7 dan 9 ke dalam kotak di bawah sehingga hasil kali dua bilangan yang terbentuk menghasilkan bilangan yang sebesar mungkin.

\section{BAB II GEOMETRI}

PILIHAN GANDA: Pilihlah salah satu jawaban yang tepat.

1. Titik-titik $A, B$, dan $C$ berada pada satu garis dengan titik B di antara titik A dan titik C. Jika panjang $\mathrm{AB}=10 \mathrm{~cm}$ dan $\mathrm{BC}=5,2 \mathrm{~cm}$, jarak antara titik tengah $\mathrm{AB}$ dengan titik tengah $\mathrm{AC}$ adalah ....
A. $2,4 \mathrm{~cm}$
B. $2,6 \mathrm{~cm}$
C. $5,0 \mathrm{~cm}$
D. $7,6 \mathrm{~cm}$

ESSAY: Kerjakan soal-soal berikut dan tuliskan langkah-langkahnya.

1. Berapakah jumlah seluruh sudut dalam dari segilima beraturan ABCDE di bawah ini?

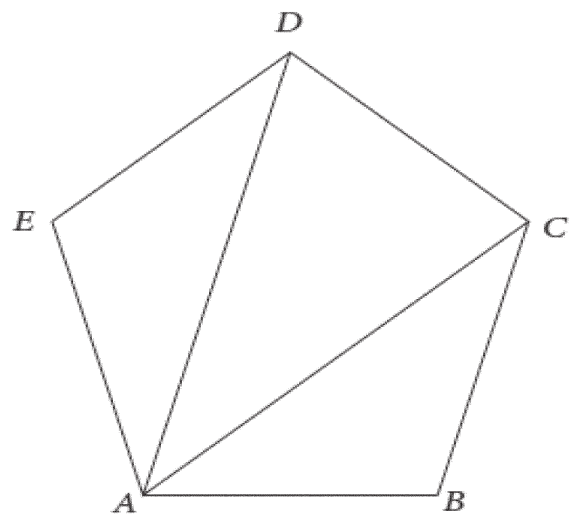

guru, dalam hal ini guru sudah tahu jawabannya, pilihan-pilhan yang jelas nggak relevan perlu diganti. Demikian juga mengenai jawaban yang tidak setipe, dipandang pasti tidak akan dipilih siswa, sehingga ini dipandang pengecoh yang kurang baik. Mengenai posisi tabel yang kemunculannya sebaiknya disesuaikan dengan kemunculannya dalam kalimat pertanyaannya, memang 
ini akan memudahkan pemahaman siswa, namun peneliti memandang bahwa kemampuan siswa membaca tabel di posisi yang sedikit terpisah dari teks harus mampu dipahami.

Dalam pengembangan soal serupa yang dilakukan Anisah dkk (2011), Rizta dkk (2013) dan Aisyah (2013), pada umumnya masih mengembangkan soal dalam jumlah yang masih terbatas sekitar 15 soal dan fokus pada materi ataupun domain tertentu. Sementara dalam penelitian ini sudah dikembangkan melalui proses adaptasi dari soal TIMSS, soal sebanyak 127, yang meliputi semua ranah dalam TIMSS, baik ranah materi maupun ranah kognitif. Akan tetapi dalam penge,bangan di sini baru sampai tahap valid, yaitu sampai tahap revisi soal berdasarkan masukan dan diskusi dengan validator. Sementara dalam ketiga penelitian Anisah, dkk (2011), Rizta, A., dkk (2013) dan Aisyah (2013) sudah sampai tahap praktis, di mana sudah diujicobakan kepada siswa dan sudah dilakukan analisis lebih mendalam. Untuk itu dalam penelitian mendatang akan dilakukan ujicoba untuk mengetahui dan merevisi aspek praktis dari soal yang telah dikembangkan, dan juga uji efek potensial dan kesulitan-kesulitan yang dialami siswa dalam merepresentasikan ideide matematika.

Johar (2011) mengembangkan soal model PISA membahas literasi matematika, yaitu kemampuan seseorang individu merumuskan, menggunakan, dan menafsirkan matematika dalam berbagai konteks. Termasuk di dalamnya bernalar secara matematis dan menggunakan konsep, prosedur, fakta, dan alat matematika dalam menjelaskan serta memprediksi fenomena. Dengan demikian pengembangan soal model TIMSS ini juga diharapakan dapat membantu meningkatkan literasi matematika siswa, jika digunakan dalam proses pembelajarannya. Dalam Kemendikbud (2013a), juga diamanatkan bahwa dalam pelaksanaan Kurikulum 2013, hendaknya tidak hanya berorientasi pada kalkulasi dan berfikir prosedural yang kering dengan penalaran, komunikasi, dan kemampuan pemecahan masalah. Untuk itu dalam implementasinya di kelas nanti, jika guru memperhatikan hal tersebut dan mulai membiasakan dengan soal-soal model TIMSS, diharapkan dapat meningkatkan skor TIMSS siswa Indonesia.

\section{SIMPULAN}

Dengan mempelajari soal-soal TIMSS yang sudah ada telah dapat diadaptasi menjadi soal-soal model TIMSS untuk kurikulum 2013 Matematika kelas VII. Buku soal (prototipe I) yang disusun dengan pengelompokan bab mengikuti ranah materi seperti dalam TIMSS, yakni Bilangan, Geometri, Aljabar, Data dan Peluang. Untuk buku soal yang dihadapi siswa tidak perlu ada bagian-bagian yang menuliskan tentang ranah materi, topik pokok dan ranah kognitif. Keterangan bagian-bagian tersebut hanya diberikan untuk buku pegangan guru.

Prototipe I divalidasi oleh pakar dan guru matematika melalui $F G D$, untuk direvisi menjadi prototipe II. Untuk hasil penilaian, validasi content masuk dalam kategori baik sekali, validasi constuct masuk dalam kategori baik, dan validasi bahasa masuk dalam kategori sedang. Adapun masukan-masukan untuk perbaikan adalah sebagai berikut: (a) soal sebaiknya diawali dari yang relatif mudah dulu, sedang, baru yang sulit; (b) penulisan soal pilihan ganda lebih baik tidak menggunakan kalimat tanya, melainkan dengan pernyataan yang memuat titik-titik (...), baik di tengah atau diakhir kalimat; (c) soal sebaiknya tidak memuat pernyataan "jika ... maka ..."; (d) pilihan jawaban hendaknya dibuat setipe dan perlu dipertimbangkan pengecoh jawaban yang baik; (e) banyak opsi jawaban sebaiknya dibuat sama, yaitu ada 4 pilihan ganda (untuk tingkat SMP); (f) posisi tabel kemunculannya sebaiknya disesuaikan dengan kemunculannya dalam kalimat pertanyaannya.

\section{UCAPAN TERIMAKASIH}

Peneliti mengucapkan terimakasih kepada Kementrian Ristek dan Pendidikan Tinggi dukungan dana penelitian melalui hibah penelitian hibah bersaing tahun 2015, melalui Surat Perjanjian Pelaksanaan Penelitian Hibah Fundamental Nomor: 024/Penel.LPPM/III/2015, tanggal 25 Maret 2015.

\section{DAFTAR PUSTAKA}

Aisyah. 2013. "Pengembangan Soal Tipe PISA di Sekolah Menengah Pertama". Edumatica, Volume 03, Nomor 01. pp. 27 - 34. 
Anisah, Zulkardi dan Darmawijoyo. 2011. "Pengembangan Soal Matematika Model PISA Pada Konten Quantity untuk Mengukur Kemampuan Penalaran Matematis Siswa Sekolah Menengah Pertama". Jurnal Pendidikan Matematika, Volume 5, Nomor 1. pp. $1-5$.

Ina, V.S., Mullis, I., Martin, M.O., Ruddock, G.J., O'Sullivan, C.Y. and Preuschoff, C. 2009. TIMSS 2011 Assessment Frameworks. TIMSS \& PIRLS International Study Center Lynch School of Education, Boston College.

Johar, R. 2012. "Domain Soal PISA untuk Literasi Matematika". Jurnal Peluang. Volume 1, Nomor 1. pp. $30-41$.

Kementerian Pendidikan dan Kebudayaan (Kemendikbud). 2013a. Materi Pelatihan Guru Implementasi Kurikulum 2013 SMP/MTs MATEMATIKA. Badan Pengembangan Sumber Daya Manusia Pendidikan dan Kebudayaan dan Penjaminan Mutu Pendidikan.

Kementerian Pendidikan dan Kebudayaan (Kemendikbud). 2013b. Matematika SMP/ MTS Kelas VII. Jakarta: Kementerian Pendidikan dan Kebudayaan.

Kementerian Pendidikan dan Kebudayaan (Kemendikbud). 2013c. Lampiran Peraturan Menteri Pendidikan dan Kebudayaan Republik Indonesia Nomor Tahun 2013 Tentang Silabus Sekolah Menengah Pertama/
Madrasah Tsanawiyah pada Kelas VII. Badan Penelitian dan Pengembangan Pusat Kurikulum dan Perbukuan Tahun 2013.

Mullis, I., Martin, M.O., Ruddock, G.J., O'Sullivan, C.Y. and Preuschoff, C. 2009. TIMSS 2011 Assessment Framework. Chesnut Hills: Boston College.

Foy, P. and Olson, J.F., (editor). 2009. TIMSS 2007 User Guide for International Database: Released Items Mathematics-Eighth Grade. TIMSS \& PIRLS International Study Center Lynch School of Education, Boston College.

Foy, P. \& Olson, J.F., (editor). 2013. TIMSS 2011 User Guide for International Database: Released Items Mathematics-Eighth Grade. TIMSS \& PIRLS International Study CenterLynch School of Education, Boston College.

Puspendik. 2006. Laporan Hasil TIMSS 2003Matematika. Jakarta: Puspendik, Balitbang Depdiknas.

Rizta, A., Zulkardi dan Hartono, Y. 2013. "Pengembangan Soal Penalaran Model TIMSS Matematika SMP". Jurnal Penelitian dan Evaluasi Pendidikan Tahun 17, Nomor 2. pp. $230-240$.

Tessmer, Martin. 1993. Planning and Conducting Formative Evaluations. London. Kogan page. 